\section{A Leaf Disk Assay for Screening Sweet Cherry Genotypes for Susceptibility to Powdery Mildew}

\author{
James W. Olmstead and Gregory A. Lang ${ }^{1}$ \\ Irrigated Agriculture Research and Extension Center, Washington State \\ University, Prosser, WA 99350-9687
}

Gary G. Grove

Tree Fruit Research and Extension Center, Washington State University, Wenatchee, WA 98801

Additional index words. disease resistance, Prunus avium, Podosphaera clandestina

\begin{abstract}
A detached leaf disk assay for screening sweet cherry (Prunus avium L.) genotypes for susceptibility to powdery mildew (PM) [Podosphaera clandestina (Wallr.:Fr.) Lev.] was developed by evaluating the effects of photoperiod ( 24 hours light, 0 hours light, 14 hours light/10 hours dark), substrate nutrient content (sterile distilled water, 1\% sucrose), leaf age (old, young, emergent), and leaf explant size (intact leaf, $30 \mathrm{~mm}, 20 \mathrm{~mm}$ ) on PM growth on leaves from the susceptible cultivar Bing. The only parameter described that had a significant $(P \leq 0.001)$ effect on PM growth was leaf age. Old leaves, designated as the third fully expanded leaf from the basal end of current-year's shoot growth, were never infected with PM under controlled inoculations. In the absence of significant differences between treatments, those parameters with the highest treatment means were selected for subsequent evaluation. To test the leaf disk assay, 14 sweet cherry cultivars were screened in two experiments, and rated according to level of PM susceptibility. Rank sum comparison of results from cultivars used for leaf disk screening agreed with earlier field rankings of the same cultivars. The developed leaf disk assay greatly reduced the space required to screen sweet cherry cultivars, and was a repeatable and objective predictor of field resistance that may be useful for screening germplasm or breeding populations.
\end{abstract}

Powdery mildew (PM) is the most serious preharvest disease of sweet cherry in Washington State (Grove, 1991, 1998; Grove and Boal, 1991a, 1991b); it commonly infects foliage, but can also infect fruit. Fruit infections can result in severe financial losses when entire lots of fruit are rejected because of infection and reduction of fruit quality via flesh degradation (Grove, 1991). Fruit infections are more prevalent in orchards with high incidence and severity of foliar PM (Grove and Boal, 1991b).

The life cycle of the pathogen, its overwintering survival mechanism, and the environmental conditions conducive to infection have recently been characterized (Grove, 1991; Grove and Boal, 1991a, 1991b). The fungus survives in the sexual stage as cleistothecia on senescent leaves on the orchard floor, trapped in tree crotches, or in bark fissures of cherry

Received for publication 15 June 1999. Accepted for publication 29 Sept. 1999. This paper is a portion of a thesis submitted by J.W.O. in partial fulfillment of MS degree requirements at Washington State Univ. (WSU). We thank W.E. Howell, NRSP5/WSU, for providing use of field plots and trees, and K.K. Kidwell, WSU, for review, guidance, and advice. We also gratefully acknowledge the WSU College of Agriculture and Home Economics and the Washington Tree Fruit Research Commission for their financial support of this research. The cost of publishing this paper was defrayed in part by the payment of page charges. Under postal regulations, this paper therefore must be hereby marked advertisement solely to indicate this fact.

'e-mail address: glang@tricity.wsu.edu been made to characterize resistance to $P$. clandestina, although variation in susceptibility exists among cherry species and cultivars. Hedrick (1915) observed that $P$. avium and $P$. cerasus L. were susceptible, but $P$. mahaleb L. was rarely infected by PM. In Washington State, English (1947) observed that 'Lambert' and 'Napoleon' had much less PM than did 'Bing'. Infected fruit were observed on 'Bing', 'Black Tartarian', and 'Lambert' but not on 'Napoleon'. Only 'Hoy' and 'Wood' were identified as being resistant (Hedrick, 1915; Hesler and Whetzel, 1937). More recently, 'PMR-1', a chance seedling identified in the stone fruit breeding program at Washington State Univ.'s Irrigated Agriculture Research and Extension Center (IAREC) near Prosser, Wash., has proven to be immune to foliar PM infection (Toyama et al., 1993). To identify resistant cherry genotypes, a rapid, reliable, and economical method of screening is needed.

Detached leaf culture may be useful for screening cherry genotypes for PM resistance. Dependence on natural field epidemics is unreliable during years with low disease incidence (Welty and Barker, 1993). The use of controlled environment testing allows multiple screenings in a single growing season, which is otherwise impossible in a perennial tree fruit crop. Detached leaf screening has been used, with varying degrees of success, as a resistance assay for a wide range of diseases on many horticultural and agronomic crops (Brown et al., 1999; Dolar et al., 1994; Dorrance and Inglis, 1997; Fanourakis, 1990; Randhawa and Civerolo, 1985; Reddy et al., 1994; St. Amand and Wehner, 1995; Tedford et al., 1990). Detached leaf culture has been used to identify germination requirements of PM conidia on sweet cherries and peaches (Prunus persica Batsch); however, these tests were terminated before colony growth started (Grove and Boal, 1991b; Weinhold, 1961). To reliably predict resistance, detached leaf culture conditions must be conducive to optimum PM growth.

The objectives of this study were to develop a rapid, reliable, and economical cherry PM resistance screening assay based on detached leaf culture, and to utilize this assay to screen a number of existing cherry cultivars for resistance.

\section{Materials and Methods}

Culture and inoculation conditions. Detached leaves were collected in July 1998 from the known susceptible cultivar, 'Bing', from an orchard near Prosser that had not been treated with fungicide during the 1998 growing season. Only young leaves that had not yet expanded fully (emergent) were used (Grove and Boal, 1991b). Detached leaves were collected in polyethylene bags and transported on ice to the IAREC, where they were inspected visually and those showing PM symptoms were discarded. Detached leaves were surface disinfested for $30 \mathrm{~s}$ in a $70 \%$ ethanol solution, then rinsed immediately with sterile, distilled water (Spurr, 1979). Detached leaves were allowed to air-dry completely in a fume hood 
before inoculation with $P$. clandestina conidia

All inoculations were performed with a spore settling tower (Reifschneider and Boiteux, 1988), using a composite of $P$. clandestina conidial isolates (Grove and Boal, 1991b) collected from orchards near Prosser. Source leaves for inoculations were uniformly and heavily infected. Test leaves were inoculated on the abaxial side (Grove and Boal, 1991b), with each block inoculated separately. An average of 25 conidia $/ \mathrm{mm}^{2}$ were allowed to settle on the detached leaves for $5 \mathrm{~min}$ before the leaves were moved from the settling tower.

Three photoperiods ( $24 \mathrm{~h}$ light, $0 \mathrm{~h}$ light, or $14 \mathrm{~h}$ light/10 h dark) and two substrate nutrient levels (sterile distilled water or $1 \%$ sucrose) were tested initially to determine optimal conditions for pathogen development. To maintain a high relative humidity $(\mathrm{RH})$, inoculated, detached leaves were floated individually in sterile, plastic petri dishes $(100 \times 15 \mathrm{~mm})$, abaxial side up (Weinhold, 1961), on either sterile distilled water or a $1 \%$ sucrose solution. Petri dishes were placed in random order in a controlled-environment chamber (Precision Scientific Group, Chicago) with white fluorescent lights and incubated at $22 \pm 2{ }^{\circ} \mathrm{C}$ under a 24-h photoperiod [photosynthetic photon flux $(P P F) \approx 50 \mu \mathrm{mol} \cdot \mathrm{m}^{-2} \cdot \mathrm{s}^{-1}$. To accommodate the entire experiment in a single incubator, the treatments requiring complete darkness were wrapped tightly in aluminum foil, whereas treatments requiring a 14-h photoperiod were wrapped in aluminum foil for $10 \mathrm{~h}$ each day.

The experiment was designed as a twofactor experiment (photoperiod and substrate nutrient content), with treatments arranged in a randomized complete-block design. Within the controlled-environment chamber there were five replications per treatment. The number of days to first colony formation (incubation period), presence of contaminating organisms, and evidence of tissue necrosis were monitored daily. The number of $P$. clandestina colonies was counted on the 14th day using a dissecting microscope (Bausch and Lomb, Rochester, N.Y.) at 30×.

Leaf age and size. Detached 'Bing' leaves of three distinct ages were collected in July 1998, as follows: 1) old leaves (designated as the third fully expanded leaf from the base of current-year's shoot growth), 2) young leaves (designated as the first or second fully expanded leaf from the apex of current-year's shoot growth), and 3) emergent leaves (designated as those that were not yet fully expanded) (Grove and Boal, 1991b). To test for possible effects of tissue size on $P$. clandestina colonization of detached leaves, three tissue sizes (full-size leaves, and 30- and 20-mm leaf disks cut with a cork borer) were used for each leaf age group. Each tissue size was obtained from separate leaves corresponding to each leaf age.

Leaf collection, transport, and inspection were as described above, followed by cutting into the three different tissue sizes. Surface disinfestation and $P$. clandestina inoculation were performed as described previously, after cutting the leaves into different tissue sizes. After inoculation, detached leaves and leaf disks were placed singly into separate sterile petri dishes $(150 \times 15 \mathrm{~mm})$, abaxial side up. Since the substrate solutions occasionally had splashed onto the surface of the leaf tissue in the first experiment, a piece of sterile filter paper, saturated with $1 \%$ sucrose solution, was used to support the detached leaves. Petri dishes were randomized in the same controlled-environment chamber as described previously, and incubated at $22 \pm 2{ }^{\circ} \mathrm{C}$ under a 14 $\mathrm{h}$ photoperiod $\left(P P F \approx 50 \mu \mathrm{mol} \cdot \mathrm{m}^{-2} \cdot \mathrm{s}^{-1}\right)$. All treatments were monitored daily for drying of the filter paper; $1 \%$ sucrose solution was added if necessary.

The experiment was designed as a twofactor experiment (leaf age and size) with five replications per treatment. All treatments were arranged in a randomized complete-block design. The incubation period, presence of contaminating organisms, and evidence of tissue necrosis were monitored daily. Since $P$. clandestina growth by the 14th day was too extensive to discern individual colonies, the percentage of leaf area covered by powdery mildew was estimated visually using a dissecting microscope at $30 \times$.

Field screening. On 10 June 1998, mature trees of 50 sweet cherry genotypes were rated visually for susceptibility to PM under field conditions near Prosser. The trees had not been treated with fungicides during the 1998 season, and had been indexed previously as virus-free. Multiple trees were available for 13 of the genotypes. Visual ratings were made by examining the whole tree to identify a representative branch that was used to score PM colonization based on a qualitative, five level scale: 1 = NoPM; 2 = distinct leaf mottling but no visible mildew colonies; $3=\mathrm{a}$ few distinct colonies on young leaves; $4=$ large numbers of colonies on young leaves; $5=$ colonies no longer distinct, PM covering most of the leaf.

Detached leaf disk cultivar screening. The detached leaf disk procedure was used to identify differences in susceptibility of sweet cherry cultivars to $P$. clandestina. Young, emergent leaves of 14 cultivars were collected in July and Aug. 1998 from mature trees near Prosser. Included in the detached leaf screening were three cultivars ('Moreau', 'PMR-1', and 'Venus') that had shown no evidence of PM in the field, and four ('Bing', 'Lapins', 'Rainier', and 'Van') that constitute the majority of cherry production in Washington State. Two recently released cultivars from WSU/Prosser ('Chelan' and 'Tieton') were included. The remaining cultivars ('Black Republican', 'Black Tartarian', 'Lambert', 'Sam', and 'Stella'), all of either historical or minor significance in Washington State, were chosen according to their varying levels of PM susceptibility in field observations.

Emergent leaves were collected, transported, inspected, surface disinfested, and inoculated as described previously, using 30$\mathrm{mm}$ leaf disks. Following inoculation, each leaf disk was placed individually in a sterile, plastic petri dish $(150 \times 15 \mathrm{~mm})$ on a single piece of filter paper saturated with $1 \%$ sucrose solution. Petri dishes were randomized in a controlled-environment chamber maintained at $22 \pm 2{ }^{\circ} \mathrm{C}$ under a 14-h photoperiod ( $P P F$ $\left.\approx 50 \mu \mathrm{mol} \cdot \mathrm{m}^{-2} \cdot \mathrm{s}^{-1}\right)$. All treatments were monitored daily, and $1 \%$ sucrose solution was added as needed.

The experimental design was a randomized complete block within the incubator, with five replications per cultivar. The incubation period, presence of contaminating organisms, and evidence of tissue necrosis were monitored daily. On the 14th day, the percentage of leaf area covered by $P$. clandestina and presence of cleistothecia were estimated visually as before. The experiment was performed two times.

Statistical analysis. Data for the culture and inoculation condition experiment and the leaf age and size experiment were analyzed using Minitab Data Analysis Software (Minitab, State College, Pa.) with the analysis of variance (ANOVA) option. Data from both detached leaf disk cultivar experiments were analyzed using the general linear model in SAS (SAS Institute, Cary, N.C.), and treatment means were separated with Fisher's protected LSD $(P \leq 0.05)$. The Wilcoxon rank sum test (Ott, 1993), a nonparametric procedure, was used to compare ranking of the detached leaf disk screening with field observations for the cultivars.

\section{Results and Discussion}

Assay cultural conditions. The results below indicate that the simple detached leaf disk screening method described above can be used to rate the foliar susceptibility of sweet cherry cultivars to $P$. clandestina. The optimum temperature and $\mathrm{RH}$ for germination of $P$. clandestina conidia on cherry leaves was identified previously as $22^{\circ} \mathrm{C}$ and nearly $100 \% \mathrm{RH}$ (Grove and Boal, 1991b). In this study, ANOVA for the incubation period and the number of PM colonies present after $14 \mathrm{~d}$ detected no significant $(P>0.05)$ effects of photoperiod or substrate nutrient levels. The interaction between photoperiod and substrate nutrient content also was not significant $(P>$ $0.05)$. Although not significant, the shortest incubation period and highest number of PM colonies were observed with leaves cultured on $1 \%$ sucrose in a $14-\mathrm{h}$ photoperiod (Table 1 ), which resembles the natural photoperiod during field epidemics.

Previous PM germination studies in cherry (Grove and Boal, 1991b) and in peach (Weinhold, 1961) were conducted in complete darkness. Spencer (1978) also noted that plants could be infected readily with PM in darkness. However, Yarwood (1946) found 1) that detached leaves did not senesce as rapidly, and were less susceptible to contaminating fungi in light than in darkness, and 2) that adding sugar to the substrate on which leaves are kept reduces the effect of darkness. Randhawa and Civerolo (1985), in culturing detached peach leaves, found that continuous dark favored growth of contaminant organisms and resulted in extensive water-soaking of some leaves. We obtained a similar result, 
Table 1. Effects of sucrose level (in distilled water) and photoperiod on average number of days until first visible powdery mildew colony (incubation period), number of colonies present, and leaf integrity of 'Bing' cherry leaves.

\begin{tabular}{|c|c|c|c|c|c|c|}
\hline \multirow{4}{*}{$\begin{array}{l}\text { Infection } \\
\text { characteristic }\end{array}$} & \multicolumn{6}{|c|}{ Sucrose level (\%) } \\
\hline & \multicolumn{3}{|c|}{0} & \multicolumn{3}{|c|}{1} \\
\hline & \multicolumn{3}{|c|}{ Photoperiod (h) } & \multicolumn{3}{|c|}{ Photoperiod (h) } \\
\hline & 0 & 14 & 24 & 0 & 14 & 24 \\
\hline $\begin{array}{l}\text { Days until first } \\
\text { visible colony }\end{array}$ & $4.5^{\mathrm{ss}}$ & 4.4 & 4.7 & 4.6 & 3.8 & 4.8 \\
\hline $\begin{array}{l}\text { Number of colonies } \\
\text { (14 d) }\end{array}$ & $\begin{array}{c}1.6^{\mathrm{Ns}} \\
\text { Necrotic areas }\end{array}$ & $\begin{array}{c}3.0 \\
\text { No necrosis }\end{array}$ & $\begin{array}{l}3.2 \\
\text { No necrosis }\end{array}$ & $\begin{array}{c}1.2 \\
\text { Necrotic areas }\end{array}$ & $\begin{array}{c}4.6 \\
\text { No necrosis }\end{array}$ & $\begin{array}{c}2.4 \\
\text { No necrosis }\end{array}$ \\
\hline
\end{tabular}

${ }^{n}$ There were no significant differences $(P \leq 0.05)$ among means for any variables as determined by analysis of variance.

with contaminating organisms and extensive tissue necrosis occurring only in leaves cultured in complete darkness (Table 1). For all other treatments, surface disinfestation with $70 \%$ ethanol (Spurr, 1979) completely suppressed saprophytic organisms. The addition of $1 \%$ sucrose to the substrate had no significant effect on growth of PM; however, detached leaves had a higher number of mildew colonies when cultured on a $1 \%$ sucrose solution (Table 1).

Leaf age and size. The ability to select any leaf from a cherry tree to use in detached leaf disk screening would be advantageous. Fanourakis (1990), studying PM of cucumber (Cucumis sativus L.), found that mildew developed uniformly on leaves of all ages, but in our studies, leaf age was the only variable of those tested that had a significant impact on PM infection levels. The cultural conditions identified in the initial experiment as being most favorable (14-h photoperiod, $1 \%$ sucrose) resulted in so much PM growth in the second experiment that after $14 \mathrm{~d}$ the percentage of infected leaf area was estimated visually rather than by counting individual colonies. ANOVA for percentage of diseased leaf area after $14 \mathrm{~d}$ detected highly significant differences $(P \leq 0.001)$ for leaf age. Emergent cherry leaves had higher PM percentages than did older leaves in both the current study and that of Grove and Boal (1991b). Old leaves had no PM (Table 2). This agrees with field observations made in Washington State, where field epidemics end soon after harvest, a time that generally coincides with the setting of terminal buds and cessation of new growth. When data for old leaves were omitted, leaf age became nonsignificant $(P>0.05)$.

Although fully expanded, young, whole leaves had the highest percentage of mildew growth, the effect of leaf disk size was not significant. ANOVA indicated nonsignificant effects $(P>0.05)$ of leaf age, size, and the interaction between the two. There was no evidence of contaminating organisms on any leaf sample evaluated in this experiment. On all cut leaves (20- and 30-mm treatments), a small ring of necrotic tissue formed around the circumference of the leaf disks, although this appeared to have no effect on PM growth. The shortest incubation period and highest percentage of PM were found on emergent leaves cut into 20-mm disks (Table 2). Therefore, the smallest leaf disk size could be used reliably, decreasing the allotted space required to conduct the test, and thereby facilitating the use of multiple samples from a single leaf (although that was not done in these experiments).

Field screening. Of the 50 sweet cherry cultivars rated for natural infection by PM under local orchard conditions, a subset of 12 was selected to provide a wide range of genetic susceptibilities (Table 3). These were tentatively classified as highly resistant (no mildew colonies or symptoms present), moderately resistant (distinct leaf mottling but few or no actual colonies visible), slightly susceptible (a few distinct colonies visible), moderately susceptible (large numbers of colonies visible), and highly susceptible (massive colonies covering most of the leaf). This provided a range of apparent genetic diversity for subsequent testing of the reliability of the detached leaf screening procedure.

Detached leaf disk cultivar screening. Results from the two detached leaf disk screening trials were not significantly different $(P>$ 0.05 ), so the data were pooled for final statistical analyses. Cultivars with the largest PM infection areas also had the shortest incubation periods. Cleistothecia were present after $14 \mathrm{~d}$ on all cultivars except those having no incidence of disease (data not shown). Cultivars were separated by class according to Fisher's protected LSD $(P \leq 0.05)$, and rated for their susceptibility to PM colonization (Table 4). In contrast with the tentative rating classes used in the field observations, statistical analysis identified only four classes ( $a, b, c, d)$ with two intermediate subclasses (bc, cd). The 12 cultivars used for both the detached leaf disk screening and field observations were ranked from most susceptible to most resistant, and found to be statistically equal $(P \leq 0.05)$ using the Wilcoxon rank sum test. The cultivars in classes $a, b$, and $c$ in the former screening segregated similarly $(5,4$, and 3 , respectively) in the field ratings (Tables 3 and 4). Cultivars field-rated 1 or 2 were included in detached leaf statistical class d, although there is a clear distinction between cultivars that fall in this class. Both 'Lambert' and 'Black Tartarian' exhibited minor PM infection, whereas other cultivars in class d ('Chelan', 'Moreau', 'PMR1 ', and 'Venus') showed no evidence of infection in either test (Tables 3 and 4). Therefore, 'Lambert' and 'Black Tartarian' are listed as moderately resistant in Table 4 . When labeled in this manner, classes identified in the detached leaf disk screening method match those in the tentative field classification.

In four cases, cultivar classifications defined by the detached leaf disk screening method did not match classifications based on field observations. The most obvious of these was for 'Black Tartarian', a cultivar found to be highly susceptible in field observations (Table 3) but susceptible to moderately resistant in detached leaf testing (Table 4). 'Chelan' was highly resistant in detached leaf studies, a result that has not yet been confirmed in field observations. Identification of 'Lambert' as moderately resistant agrees with observations made by English (1947).

The assay conditions most conducive to PM growth in this study were whole, emergent leaves, cultured on a $1 \%$ sucrose solution at 22 ${ }^{\circ} \mathrm{C}$ for a 14-h photoperiod. Further refining the variables that promote PM growth while delaying leaf senescence may be feasible. However, the extent of the agreement between field observations and two detached leaf screening experiments demonstrates the utility of the assay conditions developed thus far.

Table 2. Effects of leaf age and size of explant on average number of days until first visible powdery mildew colony (incubation period), percentage of diseased area, and leaf integrity of 'Bing' cherry leaves.

\begin{tabular}{|c|c|c|c|c|c|c|c|c|c|}
\hline \multirow[b]{4}{*}{ Infection characteristic } & \multicolumn{9}{|c|}{ Leaf age $^{\mathrm{z}}$} \\
\hline & \multicolumn{3}{|c|}{ Emergent } & \multicolumn{3}{|c|}{ Young } & \multicolumn{3}{|c|}{ Old } \\
\hline & \multicolumn{3}{|c|}{ Explant size $^{y}$} & \multicolumn{3}{|c|}{ Explant size } & \multicolumn{3}{|c|}{ Explant size } \\
\hline & $20 \mathrm{~mm}$ & $30 \mathrm{~mm}$ & Whole & $20 \mathrm{~mm}$ & $30 \mathrm{~mm}$ & Whole & $20 \mathrm{~mm}$ & $30 \mathrm{~mm}$ & Whole \\
\hline Diseased $\operatorname{area}^{\mathrm{w}}(\%$ at $14 \mathrm{~d})$ & $60 \mathrm{a}$ & $27 \mathrm{a}$ & $51 \mathrm{a}$ & $10 \mathrm{a}$ & $22 \mathrm{a}$ & 43 a & $0 \mathrm{~b}$ & $0 \mathrm{~b}$ & $0 \mathrm{~b}$ \\
\hline Leaf integrity (14 d) & $\begin{array}{c}\text { Necrotic } \\
\text { margin }\end{array}$ & $\begin{array}{c}\text { Necrotic } \\
\text { margin }\end{array}$ & $\begin{array}{c}\text { No } \\
\text { necrosis }\end{array}$ & $\begin{array}{c}\text { Necrotic } \\
\text { margin }\end{array}$ & $\begin{array}{c}\text { Necrotic } \\
\text { margin }\end{array}$ & $\begin{array}{c}\text { No } \\
\text { necrosis }\end{array}$ & $\begin{array}{c}\text { Necrotic } \\
\text { margin }\end{array}$ & $\begin{array}{c}\text { Necrotic } \\
\text { margin }\end{array}$ & $\begin{array}{c}\text { No } \\
\text { necrosis }\end{array}$ \\
\hline
\end{tabular}

${ }^{2}$ Emergent $=$ leaves harvested before full expansion; young = first or second fully expanded leaf from apex; old = third leaf from base of current-year's growth y20- and 30-mm leaf disks cut from intact leaf.

${ }^{\mathrm{x}}$ Mean separation within parameters by ANOVA, $P \leq 0.05$.

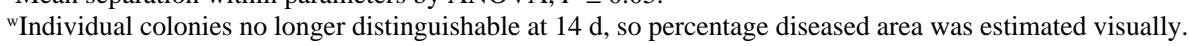


Table 3. Field observational rating and ranking of 12 cherry cultivars ${ }^{z}$ based on powdery mildew (PM) infection levels (Prosser, Wash., 10 June 1998).

\begin{tabular}{lccc}
\hline \hline Cultivar & Rating $^{\mathrm{y}}$ & Rank $^{\mathrm{x}}$ & Tentative classification \\
\hline Black Republican & 5.0 & 12 & Highly susceptible \\
Black Tartarian & 4.5 & 10.5 & Highly susceptible \\
Van & 4.5 & 10.5 & Highly susceptible \\
Bing & 4.3 & 9 & Highly susceptible \\
Rainier & $4.0^{\mathrm{w}}$ & 8 & Moderately susceptible \\
Stella & 3.3 & 7 & Slightly susceptible \\
Lapins & $3.0^{\mathrm{w}}$ & 5.5 & Slightly susceptible \\
Sam & $3.0^{\mathrm{w}}$ & 5.5 & Slightly susceptible \\
Lambert & 2.3 & 4 & Moderately resistant \\
Moreau & 1.0 & 2 & Highly resistant \\
PMR-1 & 1.0 & 2 & Highly resistant \\
Venus & $1.0^{\mathrm{w}}$ & 2 & Highly resistant
\end{tabular}

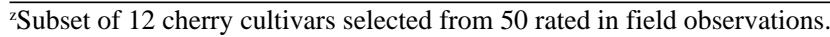

${ }^{\mathrm{y}} 1$ = no PM; 2 = distinct leaf mottling but no visible PM colonies; 3 = very few distinct colonies on young leaves; $4=$ large numbers of colonies on young leaves; and $5=$ colonies no longer distinct, PM covering most of the leaf.

${ }^{x}$ Ranking of rated cultivars for Wilcoxon rank sum test, where ties are assigned a rank equal to the average of the ranks they occupy.

${ }^{\text {w }}$ Rating based on observation of only one tree.

Table 4. Effect of cherry cultivar on mean powdery mildew area, rank, and infection susceptibility rating based on the $30-\mathrm{mm}$ detached leaf assay.

\begin{tabular}{lccc}
\hline Cultivar & Diseased area $\left(\mathrm{mm}^{2}\right)^{\mathrm{z}}$ & Rank $^{\mathrm{y}}$ & Classification \\
\hline Bing & $68 \mathrm{a}^{\mathrm{x}}$ & 12 & Highly susceptible \\
Black Republican & $61 \mathrm{a}$ & 11 & Highly susceptible \\
Sam & $57 \mathrm{a}$ & 10 & Highly susceptible \\
Rainier & $37 \mathrm{~b}$ & 9 & Moderately susceptible \\
Lapins & $23 \mathrm{bc}$ & 8 & Moderate to slightly susceptible \\
Van & $21 \mathrm{c}$ & 7 & Slightly susceptible \\
Tieton & $20 \mathrm{c}$ & --- & Slightly susceptible \\
Stella & $20 \mathrm{c}$ & 6 & Slightly susceptible \\
Black Tartarian & $12 \mathrm{~cd}$ & 5 & Slightly susceptible to moder- \\
& & & ately resistant \\
Lambert & $4 \mathrm{~d}$ & 4 & Moderately resistant \\
Chelan & $0 \mathrm{~d}$ & --- & Highly resistant \\
Moreau & $0 \mathrm{~d}$ & 2 & Highly resistant \\
PMR-1 & $0 \mathrm{~d}$ & 2 & Highly resistant \\
Venus & $0 \mathrm{~d}$ & 2 & Highly resistant
\end{tabular}

${ }^{2}$ Mean after $14 \mathrm{~d}$ incubation from two pooled experiments with five replications of each cultivar per experiment.

${ }^{\mathrm{y}}$ Ranking of rated cultivars for Wilcoxon rank sum test, where ties are assigned a rank equal to the average of the ranks they occupy.

${ }^{x}$ Mean separation among cultivars by Fisher's protected LSD, $P \leq 0.05$

\section{Literature Cited}

Brown, M.V., J.N. Moore, P. Fenn, and R.W. McNew. 1999. Comparison of leaf disk, greenhouse, and field screening procedures for evaluation of grape seedlings for downy mildew resistance. HortScience 34:331-333.

Dolar, F.S., A. Tenuta, and V.J. Higgins. 1994. Detached leaf assay for screening chickpea for resistance to Ascochyta blight. Can. J. Plant Pathol. 16:215-220.

Dorrance, A.E. and D.A. Inglis. 1997. Assessment of greenhouse and laboratory screening methods for evaluating potato foliage for resistance to late blight. Plant Dis. 81:1206-1213.

English, H. 1947. Powdery mildew on cherry fruit in
Grove, G.G. 1997. New directions in controlling cherry powdery mildew. Good Fruit Grower 48(5):27-32.

Grove, G.G. 1998. Meteorological factors affecting airborne conidia concentrations and the latent period of Podosphaera clandestina on sweet cherry. Plant Dis. 82:741-746.

Grove, G.G. and R.J. Boal. 1991a. Overwinter survival of Podosphaera clandestina in eastern Washington. Phytopathology 81:385-391.

Grove, G.G. and R.J. Boal. 1991b. Factors affecting germination of conidia of Podosphaera clandestina on leaves and fruit of sweet cherry. Phytopathology 81:1513-1518.

Gubler, W.D., H.L. Ypema, D.G. Ouimette, and L.J. Bettiga. 1996. Occurrence and development of resistance in Uncinula necator to triadimefon, myclobutanil, and fenarimol in California grapevines. Plant Dis. 80:902-909.

Hedrick, U.P. 1915. The cherries of New York. J.B. Lyon, Albany, N.Y.

Hesler, L.R. and H.H. Whetzel. 1937. Manual of fruit diseases. Macmillan, New York.

Ott, R.L. 1993. An introduction to statistical methods and data analysis. 4th ed. Duxbury Press, Belmont, Calif.

Randhawa, P.S. and E.L. Civerolo. 1985. A detached-leaf bioassay for Xanthomonas campestris pv. pruni. Phytopathology 75:10601063.

Reddy, K.S., S.E. Pawar, and C.R. Bhatia. 1994. Inheritance of powdery mildew (Erysiphe polygoni DC) resistance in mungbean (Vigna radiata L. Wilczek). Theor. Appl. Genet. 88:945948.

Reifschneider, F.J.B. and L.S. Boiteux. 1988. A vacuum-operated tower for inoculation of powdery mildew fungi. Phytopathology 78:14631465.

Spencer, D.M. 1978. The powdery mildews. Academic, New York.

Spurr, H.W. 1979. Ethanol treatment: A valuable technique for foliar biocontrol studies of plant disease. Phytopathology 69:773-776.

St. Amand, P.C. and T.C. Wehner. 1995. Greenhouse, detached-leaf, and field testing methods to determine cucumber resistance to gummy stem blight. J. Amer. Soc. Hort. Sci. 120:673680

Tedford, E.C., T.L. Miller, and M.T. Nielsen. 1990. A detached-leaf technique for detecting resistance to Phytophthora parasitica var. nicotianae in tobacco. Plant Dis. 74:313-316.

Toyama, T.K., D.R. Ophardt, W.E. Howell, and G.G. Grove. 1993. New powdery mildew resistant sweet cherry. Fruit Var. J. 47:234-235.

Weinhold, A.R. 1961. Temperature and moisture requirements for germination of conidia of Sphaerotheca pannosa from peach. Phytopathology 51:699-703.

Welty, R.E. and R.E. Barker. 1993. Reaction of twenty cultivars of tall fescue to stem rust in controlled and field environments. Crop Sci. 33:963-967.

Yarwood, C.E. 1946. Detached leaf culture. Bot. Rev. 12:1-56. 